\title{
Effect of body mass index on response to neo-adjuvant therapy in HER2-positive breast cancer: an exploratory analysis of the NeoALTTO trial
}

Serena Di Cosimo ${ }^{1 *+}$, Luca Porcu ${ }^{2+}$, Dominique Agbor-tarh ${ }^{3+}$, Saverio Cinieri ${ }^{4}$, Maria Alice Franzoi ${ }^{5}$, Maria Carmen De Santis ${ }^{6}$, Cristina Saura ${ }^{7}$, Jens Huober ${ }^{8}$, Debora Fumagalli ${ }^{9}$, Miguel Izquierdo ${ }^{10}$, Martine Piccart ${ }^{5}$, Maria Grazia Daidone ${ }^{1}$ and Evandro de Azambuja ${ }^{5}$

\begin{abstract}
Background: Obesity is a risk factor for breast cancer (BC) development, recurrence, and death. In view of this, we aimed to investigate the clinical value of obesity in BC patients treated with anti-HER2 therapies in the NeOALTTO trial, which randomized 455 patients to neo-adjuvant lapatinib, trastuzumab, or their combination plus paclitaxel.

Methods: Patients were classified according to their basal body mass index (BMI) into underweight $\left(<18.5 \mathrm{~kg} / \mathrm{m}^{2}\right)$, normal $\left(\geq 18.5 ;<25 \mathrm{~kg} / \mathrm{m}^{2}\right)$, overweight $\left(\geq 25 ;<30 \mathrm{~kg} / \mathrm{m}^{2}\right)$, and obese $\left(\geq 30 \mathrm{~kg} / \mathrm{m}^{2}\right)$ WHO categories. Univariate and multivariate logistic regression analyses were performed using BMI as a categorical variable. Pathological complete response ( $p C R$ ) and event-free survival (EFS) were the NeoALTTO primary and secondary outcomes, respectively.
\end{abstract}

Results: Among 454 patients analyzed, 14 (3\%), 220 (48\%), 137 (30\%), and 83 (18\%) were classified as underweight, normal weight, overweight, and obese, respectively; 231 (51\%) and 223 (49\%) had hormone receptor (HR)-positive and HR-negative primary tumors; 160 (35\%) achieved pCR. In the overall patient population, no association was found between BMI groups and pCR, as we reported pCR rates of $57.1 \%, 35 \%, 30.7 \%$, and $39.8 \%$ in underweight, normal weight, overweight, and obese cases, respectively. In contrast, in HR-positive tumors, overweight or obesity was generally associated with decreased likelihood of achieving a PCR independently of other clinical variables, including planned surgery, nodal status, and tumor size (odds ratio $[O R]=0.55,95 \% \mathrm{Cl} 0.30-1.01$, as compared to normal or underweight; $p=0.053$ ); notably, no differential effect of BMI with respect to $\mathrm{pCR}$ was observed in HRnegative cases (odds ratio $[\mathrm{OR}]=1.30,95 \% \mathrm{Cl} 0.76-2.23$, as compared to normal or underweight; $p=0.331$ ), resulting in a statistically significant interaction between BMI and HR status $(p=0.036)$. There was no association between $\mathrm{BMI}$ and EFS neither in the overall nor in the HR-positive population, but this analysis was under-powered.

(Continued on next page)

\footnotetext{
* Correspondence: serena.dicosimo@istitutotumori.mi.it

†Serena Di Cosimo, Luca Porcu and Dominique Agbor-tarh contributed equally to this work.

'Biomarkers Unit, Department of Applied Research and Technological Development, Fondazione IRCCS Istituto Nazionale dei Tumori, via G.A. Amadeo 42, 20133 Milano, Italy

Full list of author information is available at the end of the article
}

(c) The Author(s). 2020 Open Access This article is licensed under a Creative Commons Attribution 4.0 International License, which permits use, sharing, adaptation, distribution and reproduction in any medium or format, as long as you give appropriate credit to the original author(s) and the source, provide a link to the Creative Commons licence, and indicate if changes were made. The images or other third party material in this article are included in the article's Creative Commons licence, unless indicated otherwise in a credit line to the material. If material is not included in the article's Creative Commons licence and your intended use is not permitted by statutory regulation or exceeds the permitted use, you will need to obtain permission directly from the copyright holder. To view a copy of this licence, visit http://creativecommons.org/licenses/by/4.0/. The Creative Commons Public Domain Dedication waiver (http://creativecommons.org/publicdomain/zero/1.0/) applies to the data made available in this article, unless otherwise stated in a credit line to the data. 
(Continued from previous page)

Conclusions: NeoALTTO patients overweight or obese at baseline and with HR-positive primary BC appeared less

likely to achieve pCR after neo-adjuvant anti-HER2 therapies. This finding paves the way to future research in

targeting the interplay between HER2/HR signaling and metabolism.

Keywords: Body mass index, Neo-adjuvant treatment, HER2-positive breast cancer, Pathological complete response

\section{Introduction}

Obesity is one of the most common public health problems worldwide, and its incidence is increasing steadily over the past two decades in both developed and developing countries. Epidemiological data confirm that obesity is independently associated with an increased incidence of various solid tumors, including breast cancer $(\mathrm{BC})$, and is a poor prognostic factor in early and metastatic $\mathrm{BC}$ patients $[1,2]$.

Despite its impact on $\mathrm{BC}$ development and prognosis, few studies have investigated the predictive value of obesity for response to systemic therapies mostly focusing on unselected BC patient populations [3]. Hence, it is not surprising that the association between obesity and treatment response is still controversial.

In HER2-positive early BC patients, no significant difference was reported between obese and non-obese patients treated in the N9831 adjuvant trial, which compared anthracycline/taxane-based regimen versus its combination with trastuzumab, as the trend toward decreased disease-free survival observed in obese patients treated with chemotherapy alone was reverted by combining chemotherapy with trastuzumab [4]. In the neoadjuvant setting, the relationship between obesity and response to anti-HER2 agents has been evaluated mainly by retrospective or institutional series, which reported that obesity can independently and negatively affect response rate, including pathological complete response (pCR) [5-7].

Here, we sought to analyze if the relationship between obesity and adverse clinical and pathological characteristics, primary treatment response, and disease outcome in HER2-positive early BC patients treated in the setting of a large prospective randomized clinical trial such as NeoALTTO [8].

\section{Materials and methods}

Details of the NeoALTTO (Breast International Group 1-06) trial have been already reported [8]. Briefly, the study was a randomized, multicenter, open-label, phase III trial evaluating lapatinib $(\mathrm{L})$, trastuzumab $(\mathrm{T})$, or their combination $(\mathrm{L}+\mathrm{T})$ with paclitaxel as neo-adjuvant therapy in 455 patients with HER2-positive primary $\mathrm{BC}>2$ $\mathrm{cm}$. Primary objective was the rate of pathological complete response (pCR), defined as the absence of residual invasive cancer in breast surgical specimens
(ypT0/is). Secondary endpoints included event-free survival (EFS) as defined per protocol. The present study tested whether as compared to normal and/or underweight, obese/overweight HER2-positive BC patients were less likely to attain $\mathrm{pCR}$ overall and/or with respect to other clinical variables, including primary tumor hormone receptor (HR) status. The hypothesis was that obesity/overweight would be associated with reduced response to $\mathrm{L}, \mathrm{T}$, and $\mathrm{L}+\mathrm{T}$ plus paclitaxel and that this detrimental effect could be more prominent in HRpositive cases.

\section{Statistical analysis}

BMI was calculated as baseline weight in kilograms divided by the square of height in meters $\left(\mathrm{kg} / \mathrm{m}^{2}\right)$, and groups were separated into underweight $\left(<18.5 \mathrm{~kg} / \mathrm{m}^{2}\right)$, normal $\left(\geq 18.5 ;<25 \mathrm{~kg} / \mathrm{m}^{2}\right)$, overweight $(\geq 25 ;<30 \mathrm{~kg} /$ $\left.\mathrm{m}^{2}\right)$, and obese $\left(\geq 30 \mathrm{~kg} / \mathrm{m}^{2}\right)$ according to the WHO classification [9]. To test interaction with the HR status, BMI was dichotomized into underweight/normal vs overweight/obese. The association between BMI and other clinical and pathological characteristics at baseline was evaluated using Pearson's chi-squared test and Kruskal-Wallis test for categorical and continuous variables, respectively. The impact of the covariates on $\mathrm{pCR}$ was modeled with logistic regression. In multivariable logistic regression models, odds ratios (ORs) were adjusted by primary tumor size, nodal status, and planned surgery. Results were presented as ORs with 95\% confidence intervals (CIs). Median (IQR) follow-up was estimated using the reverse Kaplan-Meier method. Survival curves were estimated by the Kaplan-Meier method. Survival outcomes were analyzed using the Cox proportional hazards model. All analyses were performed using SAS 9.4 software (Copyright (c) 2016 by SAS Institute Inc., Cary, NC, USA).

\section{Results}

\section{Patient characteristics}

All but one NeoALTTO patients $(n=454)$ had known BMI before starting neo-adjuvant therapy and were included in the present analysis. Patient and tumor characteristics overall and according to BMI are depicted in Table 1. Patients were categorized as underweight, normal, overweight, and obese in 14 (3\%), 220 (48\%), 137 (30\%), and 83 (18\%) cases, 
Table 1 NeoALTTO patient characteristics by body mass index (BMI) categories

\begin{tabular}{|c|c|c|c|c|c|c|}
\hline & \multirow{2}{*}{$\begin{array}{l}\text { Overall } \\
(N=454)\end{array}$} & \multicolumn{4}{|l|}{ BMI categories } & \multirow[b]{2}{*}{$p$ value } \\
\hline & & $\begin{array}{l}\text { Underweight } \\
(N=14)\end{array}$ & $\begin{array}{l}\text { Normal weight } \\
(N=220)\end{array}$ & $\begin{array}{l}\text { Overweight } \\
(N=137)\end{array}$ & Obese $(N=83)$ & \\
\hline Median age (years) at baseline & 50 & 46 & 48 & 51 & 52 & $<0.001$ \\
\hline \multicolumn{7}{|l|}{ Randomized arm, $N(\%)$} \\
\hline L & $153(34)$ & $1(7)$ & $83(38)$ & $49(36)$ & $20(24)$ & \multirow[t]{3}{*}{0.099} \\
\hline T & $149(33)$ & $6(43)$ & $71(32)$ & $40(29)$ & $32(39)$ & \\
\hline$L+T$ & $152(33)$ & $7(50)$ & $66(30)$ & $48(35)$ & $31(37)$ & \\
\hline \multicolumn{7}{|l|}{ Clinical tumor size, $N(\%)$} \\
\hline$\leq 5 \mathrm{~cm}$ & $274(60)$ & $9(64)$ & $135(61)$ & $79(58)$ & $51(61)$ & \multirow[t]{2}{*}{0.887} \\
\hline$>5 \mathrm{~cm}$ & $180(40)$ & $5(36)$ & $85(39)$ & $58(42)$ & $32(39)$ & \\
\hline \multicolumn{7}{|l|}{ HR status, $N(\%)$} \\
\hline Negative & $223(49)$ & $3(21)$ & $110(50)$ & $73(53)$ & $37(45)$ & \multirow[t]{2}{*}{0.112} \\
\hline Positive & $231(51)$ & $11(79)$ & $110(50)$ & $64(47)$ & $46(55)$ & \\
\hline \multicolumn{7}{|l|}{ Menopausal status, $N(\%)$} \\
\hline Post-menopausal & $189(42)$ & $5(36)$ & $76(35)$ & $68(50)$ & $40(48)$ & \multirow[t]{4}{*}{0.036} \\
\hline Pre-menopausal & $219(48)$ & $9(64)$ & $122(55)$ & $53(39)$ & $35(42)$ & \\
\hline NA and age $<50$ & $14(3)$ & 0 & $9(4)$ & $2(1)$ & $3(4)$ & \\
\hline NA and age $\geq 50$ & $32(7)$ & 0 & $13(6)$ & $14(10)$ & $5(6)$ & \\
\hline \multicolumn{7}{|l|}{ Histology grade, $N(\%)$} \\
\hline G1 & $12(3)$ & $1(7)$ & $2(<1)$ & $5(4)$ & $4(5)$ & \multirow[t]{4}{*}{0.121} \\
\hline G2 & $171(38)$ & $8(57)$ & $91(41)$ & $48(35)$ & $24(29)$ & \\
\hline G3 & $205(45)$ & $3(21)$ & $101(46)$ & $62(46)$ & $39(47)$ & \\
\hline GX & $65(14)$ & $2(14)$ & $26(12)$ & $21(15)$ & $16(19)$ & \\
\hline \multicolumn{7}{|l|}{ Planned surgery, $N(\%)$} \\
\hline Conservative surgery & $130(29)$ & $5(36)$ & $63(29)$ & $39(28)$ & $23(28)$ & \multirow[t]{2}{*}{0.944} \\
\hline Mastectomy & $324(71)$ & $9(64)$ & $157(71)$ & $98(72)$ & $60(72)$ & \\
\hline \multicolumn{7}{|l|}{ Clinical nodal status, $N(\%)$} \\
\hline No/1 & $382(84)$ & $13(93)$ & $189(86)$ & $112(82)$ & $68(82)$ & \multirow[t]{2}{*}{0.531} \\
\hline$\geq N 2$, Nx or missing & $72(16)$ & $1(7)$ & $31(14)$ & $25(18)$ & $15(18)$ & \\
\hline
\end{tabular}

HR hormone receptor, $B M I$ body mass index, $L$ lapatinib, $T$ trastuzumab, $L+T$ lapatinib + trastuzumab, NA non-available

respectively. No significant association was found between BMI and other clinical features, with the unique exception of menopausal status and age. Obese and overweight patients were in fact more likely to be postmenopausal and older as compared to under/normal weight patients [postmenopausal status, $54 \%$ and $60 \%$ versus $36 \%$ and $40 \%$, respectively, $p=$ 0.036; median age (years), 52 and 51 years versus 46 and 48 years, respectively, $p<0.001$ ]. A slightly increased number of obese and overweight patients were also reported in dual as compared to each single agent arms: $79(36 \%)$ in $\mathrm{L}+\mathrm{T}, 69(31 \%)$ in $\mathrm{L}$, and 72 (33\%) in $\mathrm{T}$ arms $(p=0.099)$. No association was found between BMI and tumor stage $(p=0.887)$, grade $(p=0.121)$, and hormone receptor (HR) status $(p=0.112)$.

\section{Association between $\mathrm{BMI}$ and $\mathrm{pCR}$}

Overall, 160 patients (35\%) achieved a pCR at the time of surgery. The $\mathrm{pCR}$ rates in underweight, normal, overweight, and obese groups were 8/14 (57\%), 77/220 (35\%), 42/137 (31\%), and 33/83 (40\%), respectively. BMI did not significantly differ between patients with $\mathrm{pCR}$ and those with residual disease at surgery. Specifically, according to the median value, the measurements of BMI were similar among patients achieving or not pCR, median (IQR) BMI, $24.8(22.5-28.7) \mathrm{kg} / \mathrm{m}^{2}$ and $24.9(22.0-28.2) \mathrm{kg} / \mathrm{m}^{2}$ respectively (Fig. 1). As shown in Table 2, univariate logistic regression analysis confirmed that BMI measurements were not associated with pCR [OR underweight vs normal, 2.48 (95\% CI 0.83-7.39); OR overweight vs normal, 0.82 (95\%CI $0.52-1.30)$; OR obese vs normal, 1.23 (95\%CI $0.73-$ 


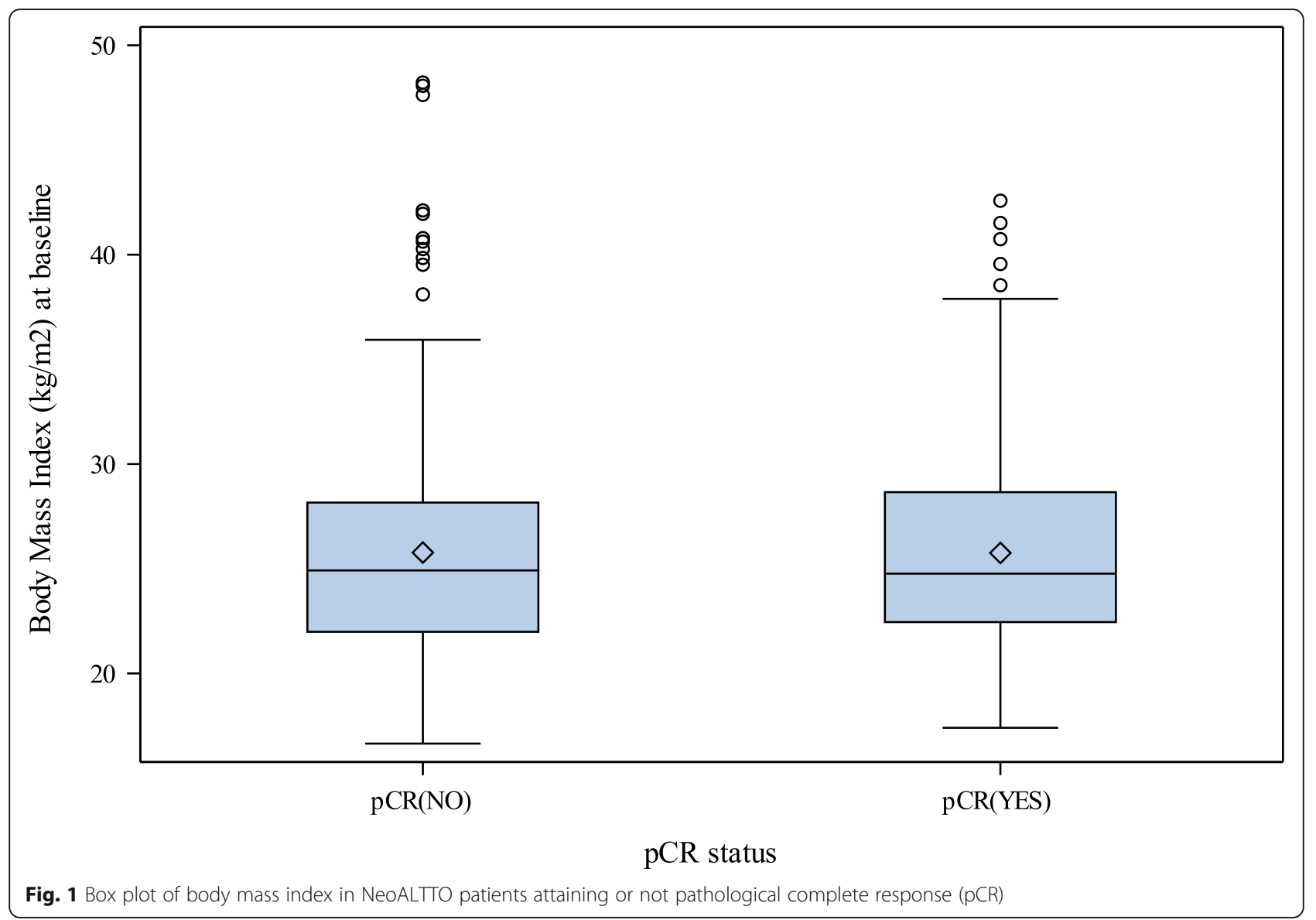

2.06); $p=0.191$ ). Point and interval estimates of ORs were substantially confirmed in multivariate analysis. As continuous variable, BMI had no discriminatory capability $(\mathrm{AUC}=0.50)$. In subgroup analysis by treatment arm, BMI was not associated to $\mathrm{pCR}$ in all treatment arms (Supp. Table 1).

\section{$\mathrm{BMI}$ and $\mathrm{pCR}$ by hormone receptor status}

While there was no evidence that BMI was an independent factor influencing the $\mathrm{pCR}$ rate in the overall NeoALTTO patient population, overweight/obese patients with HR-positive primary tumor were less likely to achieve $\mathrm{pCR}$ as compared to normal/underweight counterparts (OR 0.56, 95\%CI 0.31-1.01; $p=0.054$; Table 3). Notably, this was not the case for HR-negative cases (OR 1.31, 95\%CI 0.77-2.22; $p=0.324$ ), resulting in a statistically significant interaction between BMI and HR status $(p=0.036)$. The effect of baseline BMI on the rate of $\mathrm{pCR}$ in HR-positive cases remained worth of consideration even after adjusting for other relevant clinical variables, including tumor size, nodal status, and planned surgery (OR $0.55,95 \% \mathrm{CI} 0.30-1.01 ; p=0.053$ ).

Table 2 Effect of body mass index (BMI) on the rate of pathological complete response (pCR)

\begin{tabular}{|c|c|c|c|c|c|c|}
\hline BMI with 4 categories & pCR (\%) & $N$ & $\begin{array}{l}\text { Univariate } \\
\text { OR }(95 \% \mathrm{Cl})\end{array}$ & $\begin{array}{l}\text { Univariate } \\
p \text { value }\end{array}$ & $\begin{array}{l}\text { Multivariate }^{\wedge} \\
\text { OR }(95 \% \mathrm{Cl})\end{array}$ & $\begin{array}{l}\text { Multivariate } \\
p \text { value }\end{array}$ \\
\hline BMI at baseline & $160(35.2)$ & 454 & & & & \\
\hline Normal weight & $77(35.0)$ & 220 & - & - & - & - \\
\hline Underweight & $8(57.1)$ & 14 & $2.48(0.83-7.39)$ & 0.104 & $3.30(1.07-10.12)$ & 0.037 \\
\hline Overweight & $42(30.7)$ & 137 & $0.82(0.52-1.30)$ & 0.398 & $0.78(0.49-1.25)$ & 0.309 \\
\hline Obese & $33(39.8)$ & 83 & $1.23(0.73-2.06)$ & 0.443 & $1.28(0.75-2.18)$ & 0.362 \\
\hline
\end{tabular}

$B M I$ body mass index, $p C R$ pathological complete response, $O R$ odds ratio, $C l$ confidence interval

${ }^{\wedge}$ Adjusted for planned surgery, HR, nodal status, and tumor size 
Table $3 \mathrm{BMl}$ and hormone receptor status as predictive factors of $\mathrm{pCR}$

\begin{tabular}{|c|c|c|c|c|c|c|}
\hline \multirow[b]{2}{*}{ BMI categories } & \multirow[b]{2}{*}{$N$} & \multirow[b]{2}{*}{ pCR (\%) } & \multicolumn{2}{|l|}{ Univariate analysis } & \multicolumn{2}{|c|}{ Multivariate analysis ${ }^{\circ}$} \\
\hline & & & OR $(95 \% \mathrm{Cl})$ & $p$ value & OR $(95 \% \mathrm{Cl})$ & $p$ value \\
\hline HR-positive population & 231 & $62(26.8)$ & & & & \\
\hline Underweight/normal & 121 & $39(32.2)$ & 1 & & 1 & \\
\hline Overweight/obese & 110 & $23(20.9)$ & $0.56(0.31-1.01)$ & 0.054 & $0.55(0.30-1.01)$ & 0.053 \\
\hline HR-negative population & 223 & $98(43.9)$ & & & & \\
\hline Underweight/normal & 113 & $46(40.7)$ & 1 & 0.324 & 1 & 0.331 \\
\hline \multirow[t]{3}{*}{ Overweight/obese } & 110 & $52(47.3)$ & $1.31(0.77-2.22)$ & & $1.30(0.76-2.23)$ & \\
\hline & & & $p$ value $H R+$ vs $H R-$ & $<0.0001$ & & \\
\hline & & & $p$ value for interaction & 0.036 & & \\
\hline
\end{tabular}

$B M I$ body mass index, $p C R$ pathological complete response, $H R$ hormone receptor, $O R$ odds ratio, $C l$ confidence interval

Adjusted for planned surgery, nodal status, and tumor size

\section{Association between BMI and EFS}

After a median follow-up of 6.7 years (IQR 5.8-6.8), 127 (28.0\%) EFS events were observed. Death occurred in 77 (17.0\%) patients. Baseline BMI, either as a continuous or a categorical variable, was not significantly associated with EFS (overall or in the HR-positive cohort) (Supp. Fig. 1). Of note, this analysis was underpowered.

\section{Discussion}

The neo-adjuvant setting best suits the purpose of investigating new treatments and potential factors influencing response. In addition, pCR represents an important surrogate marker for favorable prognosis in HER2-positive breast cancer patients [10]. In this work, we investigated the impact of BMI on pCR following treatment with $\mathrm{L}$, $\mathrm{T}$, and their combination plus paclitaxel in HER2positive $\mathrm{BC}$ patients enrolled in the large randomized phase III study NeoALTTO. Half of the study patient population had a BMI in the healthy 18.5-25 range and reported a pCR rate of $35 \%$. Notably, underweighted cases $(\mathrm{BMI}<18.5)$, although few, appeared almost twice as likely to attain a pCR. Patients with a $\mathrm{BMI}<18.5$ are generally underrepresented in $\mathrm{BC}$ epidemiological [11] and clinical studies [3], at least in the western world countries. The scenario is different in Asia where up to $7 \%$ of $\mathrm{BC}$ cases are newly diagnosed in underweighted patients [12]. Whether the observed effect of underweight on PCR rate is genuine needs further investigation in pooled analysis sufficiently large to allow adjustment for confounding factors [11].

Notably, BMI was associated with decreased pCR rates in HR-positive but not in HR-negative cases, with a significant test for interaction. This result was found in the context of the anthracycline-free chemotherapeutic regimen of NeoALTTO and should be confirmed in other HER2 BC populations, where pCR rate are expected to be higher. Nevertheless, the data is not only in line with that reported with standard neoadjuvant chemotherapy
[3], showing an effect of BMI on pCR rate limited to luminal breast cancer cases, but also consistent with previous studies, showing that a BMI above normal limits has negative impact on prognosis of HR-positive BC [3].

.The effect is particularly evident when treatment consists of aromatase inhibitors [13], though recently it has been also reported with fulvestrant [14]. This evidence may be explained by the endocrine role of adipose tissue, which is involved in the metabolism of female reproductive hormones. In fact, fatty cells have their own aromatase activity, which is a significant source of estrogens in particular in menopausal women. Moreover, insulin resistance is a frequent condition in obese patients, and an intense cross-talk between insulin and estrogen signaling pathways has already been demonstrated [15]. High levels of insulin and insulin-like growth factors (IGFs) may also play direct role in stimulating tumor proliferation in obese women, independently from sexual hormone pathways $[15,16]$.

Clinical trials are currently ongoing exploring combined insulin and IGF-1 receptors targeting, or simultaneous use of anti-IGF-1 and 2 antibodies [17, 18]. These strategies might be valuable to hamper both insulin and IGF signaling, and the compensatory mechanisms triggered by single receptor blockade, which may explain the failure of previous anti-IGF-1R development [17]. According to the upcoming results, we could foresee the potential of developing specific treatments for overweight/obese patients by combining such treatment with anti-HER2 therapies, in at least 20\% of HER2-positive cases, which also co-express IGF-1R. However, it is important to mention that, in contrast to preclinical studies [19], a post hoc analysis of the N9831 study did not detect a difference in the benefit of adjuvant trastuzumab according to IGF1R protein status measured by immunohistochemistry [20]. Until more evidence becomes available, dietary and behavior modification, including increased aerobic and strength training exercise, are 
recommended to prevent weight gain, reduce biomarkers associated with inflammation and comorbidities, and improve lifestyle function status [21].

Overall, these data offer plausible biological reasons for the lower $\mathrm{pCR}$ rate observed in the luminal-like HER2-positive breast cancer patients with high BMI treated in the NeoALTTO. This is particularly interesting if we consider that HER2 has always been accounted as a factor of endocrine resistance in $\mathrm{BC}$, with the capability of attenuating the effects of endocrine therapy [22], and suggests that hormonal metabolic pathway is still active in HER2-positive tumors and plays a role in determining the behavior of disease, even in presence of adequate HER2 blockade.

\section{Conclusion}

In the NeoALTTO study, obesity and overweight are associated with reduced chance of attaining PCR in HER2positive luminal $\mathrm{BC}$ patients. This finding paves the way to future research in developing combined neo-adjuvant strategies aimed at obtaining a complete blockade of driving growth factor signals for metabolism via both HER and hormone receptors.

\section{Supplementary information}

Supplementary information accompanies this paper at https://doi.org/10 1186/s13058-020-01356-w.

Additional file 1: Supp. Table $1 \mathrm{pCR}$ rate according to BMI categories and treatment arms.

Additional file 2: Supp. Figure 1 KM curve of Event free survival by BMI categories.

\section{Acknowledgements}

SDC is the recipient of the IG 20774 grant from Fondazione Associazione Italiana Ricerca sul Cancro. Authors are indebted for his precious assistance to Dr. Antonio Cannarozzo and his collaborators from the Department of General and Legal Affairs of Fondazione IRCCS Istituto Nazionale dei Tumori - Milano.

\section{Authors' contributions}

SDC, EA, LC, and DAT were responsible for the conceptualization of the work. DAT and SC performed the statistical analyses. SDC, LP, MAF, MACS, $\mathrm{CS}, J \mathrm{H}, \mathrm{DF}, \mathrm{MI}, \mathrm{MP}, \mathrm{MGD}$, and EA analyzed the data and participated in the writing and reviewing of the manuscript. All authors read and approved the final manuscript.

\section{Funding}

The NeoALTTO study was sponsored by GlaxoSmithKline from its inception until November 30, 2015, and by Novartis since then. Lapatinib is an asset of Novartis AG as of March 2, 2015. Funding sources had no involvement in the study design, data collection, analysis and interpretation, writing of the report, and decision to submit the article for publication.

\section{Availability of data and materials}

Due to Informed Consent Form, data privacy, and Intellectual Property Rights-related restrictions, the clinical data cannot be made public, i.e., accessible for anyone, for any purpose without a review process and without putting an agreement in place. Nevertheless, raw data are available upon request and any requests can be directed to the central (Neo) ALTTO team.

\section{Ethics approval and consent to participate}

The NeoALTTO trial (Breast International Group 01-06) is a randomized, multicenter, open-label, phase 3 study. From Jan 5, 2008, to May 27, 2010, 455 patients entered the study from 86 sites in 23 countries in Europe, Asia, North and South America, and South Africa. The ethics committee and relevant health authorities at each participating institution approved the study protocol. All women gave written informed consent before study entry.

Patients' participation in this sub-study was allowed after signing the main study consent form, which included a non-specific clause for use of clinical data for secondary analyses.

\section{Consent for publication}

This manuscript does not include any individual person's details, so patient consent for publication is not applicable in this case. All authors listed and the NeoALTTO steering committee approved the present manuscript and consented for its publication.

\section{Competing interests}

SDC reports honoraria and advisory board from Novartis and Pierre-Fabre outside the scope of this work. DF received support for his Institution from GlaxoSmithKline until November 30, 2015, and from Novartis since then for the conduction of the NeoALTTO study, from AstraZeneca, Pfizer, Roche/ Genentech, Servier, and Tesaro outside the submitted work. EdA reports honoraria and advisory board from Roche/GNE, Novartis, and Seattle Genetics; travel grants from Roche/GNE and GSK/Novartis; and research grant to his institution from Roche/GNE, Astra-Zeneca, GSK/Novartis, and Servier. CS, MAF, LP, DAT, SC, MCS, and MGD have no conflicts of interest to declare. HJ received honoraria from Roche, Novartis; advisory board from Roche, Novartis; and travel support from Roche, Novartis. MI is an employee of Novartis and has stock or other ownership: Novartis. MP declared the following: Board Member (Scientific Board): Oncolytics, Radius; Consultant (honoraria): AstraZeneca, Camel-IDS, Crescendo Biologics, Debiopharm, G1 Therapeutics, Genentech, Huya, Immunomedics, Lilly, Menarini, MSD, Novartis, Odonate, Oncolytics, Periphagen, Pfizer, Roche, Seattle Genetics; research grants to her institute: AstraZeneca, Lilly, MSD, Novartis, Pfizer, Radius, Roche-Genentech, Servier, Synthon; MGD has no conflicts of interest to declare.

\section{Author details}

${ }^{1}$ Biomarkers Unit, Department of Applied Research and Technological Development, Fondazione IRCCS Istituto Nazionale dei Tumori, via G.A. Amadeo 42, 20133 Milano, Italy. ${ }^{2}$ Laboratory of Methodology for Clinical Research, Department of Oncology, Istituto di Ricerche Farmacologiche Mario Negri IRCCS, Milano, Italy. ${ }^{3}$ Frontier Science (Scotland) Ltd, Kincraig, UK. ${ }^{4}$ San Antonio Perrino Hospital, Brindisi, Italy. Institut Jules Bordet and I'Universitè Libre de Bruxelles (U.LB), Brussels, Belgium. 'Radiation Oncology, Fondazione IRSCCS Istituto Nazionale dei Tumori, Milano, Italy. ${ }^{7}$ Vall d'Hebron Institute of Oncology, Barcelona, Spain. ${ }^{8}$ University of UIm, UIm, Germany. ${ }^{9}$ Breast International Group (BIG), Boulevard de Waterloo 76, 1000 Bruxelles, Belgium. ${ }^{10}$ Oncology Clinical Development, Oncology Business Unit, Novartis Pharma AG, Basel, Switzerland.

Received: 10 July 2020 Accepted: 13 October 2020

Published online: 27 October 2020

\section{References}

1. Brown KA, Simpson ER. Obesity and breast cancer: progress to understanding the relationship. Cancer Res. 2010;70:4.

2. Chan DSM, Vieira AR, Aune D, Bandera EV, Greenwood DC, McTiernan A, et al. Body mass index and survival in women with breast cancer-systematic literature review and meta-analysis of 82 follow-up studies. Ann Oncol. 2014;25:1901-14.

3. Fontanella C, Lederer B, Gade S, Vanoppen M, Blohmer JU, Costa SD, et al. Impact of body mass index on neoadjuvant treatment outcome: a pooled analysis of eight prospective neoadjuvant breast cancer trials. Breast Cancer Res Treat. 2015;150:127-39.

4. Crozier JA, Moreno-Aspitia A, Ballman KV, Dueck AC, Pockaj BA, Perez EA. Effect of body mass index on tumor characteristics and disease-free survival in patients from the HER2-positive adjuvant trastuzumab trial N9831. Cancer. 2013;119:2447-54.

5. Chen S, Chen C-M, Zhou Y, Zhou R-J, Yu K-D, Shao Z-M. Obesity or overweight is associated with worse pathological response to neoadjuvant 
chemotherapy among Chinese women with breast cancer. PLoS One. 2012; 7:e41380.

6. Litton JK, Gonzalez-Angulo AM, Warneke CL, Buzdar AU, Kau S-W, Bondy M, et al. Relationship between obesity and pathologic response to neoadjuvant chemotherapy among women with operable breast cancer. JCO Am Soc Clin Oncol. 2008;26:4072-7.

7. Del Fabbro E, Parsons H, Warneke CL, Pulivarthi K, Litton JK, Dev R, et al. The relationship between body composition and response to neoadjuvant chemotherapy in women with operable breast cancer. Oncologist. 2012;17:1240-5.

8. Baselga J, Bradbury I, Eidtmann H, Di Cosimo S, de Azambuja E, Aura C, et al. Lapatinib with trastuzumab for HER2-positive early breast cancer (NeoALTTO): a randomised, open-label, multicentre, phase 3 trial. Lancet. 2012;379:633-40

9. World Health Organization - Nutrition - Body mass index classification. 2020 Available from: https://www.euro.who.int/en/health-topics/diseaseprevention/nutrition/a-healthy-lifestyle/body-mass-index-bmi.

10. Bardia A, Baselga J. Neoadjuvant therapy as a platform for drug development and approval in breast cancer. Clin Cancer Res. 2013;19:6360

11. Jiralerspong S, Goodwin PJ. Obesity and breast cancer prognosis: evidence, challenges, and opportunities. JCO. Am Soc Clin Oncol. 2016;34:4203-16.

12. Leong SPL, Shen Z-Z, Liu T-J, Agarwal G, Tajima T, Paik N-S, et al. Is breast cancer the same disease in Asian and Western countries? World J Surg. 2010;34:2308-24.

13. Ioannides SJ, Barlow PL, Elwood JM, Porter D. Effect of obesity on aromatase inhibitor efficacy in postmenopausal, hormone receptor-positive breast cancer: a systematic review. Breast Cancer Res Treat. 2014;147:237-48.

14. Gevorgyan A, Bregni G, Galli G, Ganzinelli M, Martinetti A, Lo Vullo S, et al. Body mass index and clinical benefit of fulvestrant in postmenopausal women with advanced breast cancer. Tumori. 2016;102:e11-4.

15. Schmidt S, Monk JM, Robinson LE, Mourtzakis M. The integrative role of leptin, oestrogen and the insulin family in obesity-associated breast cancer: potential effects of exercise. Obes Rev. 2015;16:473-87.

16. Vona-Davis L, Rose DP. Type 2 diabetes and obesity metabolic interactions: common factors for breast cancer risk and novel approaches to prevention and therapy. Current Diabetes Reviews. 2012;8:116-30.

17. Salisbury TB, Tomblin JK. Insulin/Insulin-like growth factors in cancer: new roles for the aryl hydrocarbon receptor, tumor resistance mechanisms, and new blocking strategies. Front Endocrinol (Lausanne). 2015;6:12.

18. Brahmkhatri VP, Prasanna C, Atreya HS. Insulin-like growth factor system in cancer. Novel Targeted Therapies. 2015;2015:538019.

19. McDermott MSJ, Canonici A, Ivers L, Browne BC, Madden SF, O'Brien NA et al. Dual inhibition of IGF1R and ER enhances response to trastuzumab in HER2 positive breast cancer cells. Int J Oncol. 2017;50:2221-8.

20. Reinholz MM, Chen B, Dueck AC, Tenner K, Ballman K, Riehle D, et al. IGF1R protein expression is not associated with differential benefit to concurrent trastuzumab in early-stage HER2(+) breast cancer from the North Central Cancer Treatment Group (Alliance) Adjuvant Trastuzumab Trial N9831. Clin Cancer Res. 2017;23:4203-11.

21. Demark-Wahnefried W, Campbell KL, Hayes SC. Weight management and its role in breast cancer rehabilitation. Cancer. 2012;118:2277-87.

22. Lousberg L, Collignon J, Jerusalem G. Resistance to therapy in estrogen receptor positive and human epidermal growth factor 2 positive breast cancers: progress with latest therapeutic strategies. Ther Adv Med Oncol. 2016;8:429-49.

\section{Publisher's Note}

Springer Nature remains neutral with regard to jurisdictional claims in published maps and institutional affiliations. 